\title{
ANNA PÁVLOVA EN MÉXICO
}

Alberto Dallal

\section{¡Viene la Pávlova!}

1919. La gran bailarina Anna Pávlova, cuya fama y gloria se había extendido por todo el planeta, vendría a México. Los avatares de la Revolución no dejaron que la visita de la gran bailarina causara en la Ciudad de México el revuelo esperado - principalmente por los empresarios-, pero la causa fundamental del reducido interés que causaba la noticia se debía, principalmente, a la ausencia de información básica, en este país, en torno a las diferencias entre la danza teatral "culta" - cuyo máximo exponente mundial nos hacía el honor de llegar- y la danza teatral "acompañante" de óperas, protagonistas de los intermedios entre una y otra obra de teatro, complemento de zarzuelas y elemento fundamental de piezas cortas y divertidas - gran tradición en tandas, revistas, sketches y variedades- cuyas raíces se encontraban en las brillantes, imaginativas y populares tonadillas escénicas, en auge durante el siglo XVIII, tanto en España como en México.

La gran Pávlova era la más grande bailarina clásica reconocida en ese momento en todo el mundo. Había nacido en 1881 (según su esposo, Víctor Dandré, la fecha es el 31 de enero de $1882^{1}$ ), en San Petersburgo -ciudad que, en 1918, un año antes de la visita de la Pávlova a México, dejaba de ser la capital de la leyenda llamada Unión de Repúblicas Socialistas Soviéticas-, había estudiado en la Escuela Imperial de Ballet en 1891 y ascendido con rapidez inusitada y con excepcional ahínco a primera bailarina del Teatro Marynski. Entre 1903 y 1919 Pávlova había ascendido de manera fulgurante. En 1907 realizó su primera salida fuera del país como gran bailarina (Riga, Helisingfor, Estocolmo, Copenhague, Praga y Berlín), lo cual significaba que abandonaba Rusia - jamás regresó- para bailar en los principales centros europeos. Durante la primera Guerra Mundial (1914) se dedicó a viajar por los Estados Unidos, Norte y Suramérica y sólo regresó a Europa cinco años después.

Creadora de su propia compañía, Pávlova "abre brecha" en cuanto a

1 NPD, 65 (2a. p.). 
forjar una personalidad artística única, profesional, vastamente dotada y dueña de una técnica impecable; fue famosa porque ningún papel, ya fuera del ballet clásico o del ballet romántico, parecía exigirle ningún esfuerzo de interpretación; también porque tuvo buen cuidado de rodearse -en su propia compañía- de bailarines y coreógrafos muy bien preparados y talentosos, entre otros, Michael Fokine, Paul Gerdt, Samuel Andrianoff, Nicholas Legat, Adolph Bolm, Mikhail Mordkin, Laurent Novikov, Alexandre Volinine y otros. Su responsabilidad al ofrecer espectáculos vastos, precisos, completos en el sentido técnico del término, la había adquirido durante sus años de trabajo con la compañía de Serge Diaghilev, primer "gran productor" del siglo XX en las artes del espectáculo, en cuya compañía Pávlova había bailado con Fokine, Nijinsky y Theodore Kosloff.

$\mathrm{El}$ arrebato nacionalista que imperaba en México -y que llegaba a convertirse en verdadera cruzada en algunos sectores de la actividad educativa y cultural - no permitió visualizar con profundidad la importancia de la visita de la Pávlova. Sólo núcleos muy precisos de la crítica y el periodismo y sectores de la élite artística y cultural valoraron la noticia de su llegada. Ante la relativa indiferencia de los "medios artísticos", no podían aducirse sólo las ganancias económicas de sus actuaciones, toda vez que los mexicanos estaban acostumbrados a recibir con alboroto toda clase de visitantes extranjeros. Por otra parte, la experiencia mexicana en lo que a espectáculos del escenario se trataba, no estaba exenta de sabiduría - ni los críticos especializados tampoco-; se sabía discenir entre lo bueno y lo malo, entre un cantante de ópera - por ejemplo- que intenta "dar lo mejor de sí mismo" en México y otro que, ante las circunstancias y los espacios en que tiene que actuar, hace que desmerezcan sus actitudes artísticas. Al barítono Titta Ruffo se le achacaban, por ejemplo, pecados de lesa artisticidad poco antes de que se anunciaran las presentaciones de la excelsa Pávlova.

\section{Primera incursión mexicanista de la Pávlova}

Pero Anna Pávlova llega a México y en variados escenarios hace una serie de presentaciones que embelesan y sorprenden al público mexicano. La empresa contratante (Luna Echegaray) fracasa económicamente porque la compañía de ballet ruso de la Pávlova debe alternar, al principio indiscrinadamente, con los núneros y espectáculos de Titta Ruffo, la fa- 
milia de Ricardo Bell (clowns) y otros artistas que ya gozaban del favor del público local. Los críticos de la época (Carlos González Peña, Xavier Sorondo, Xavier de Bradomín, Roberto "El Diablo" etc.) captan, reconocen y elogian el genio de la Pávlova, pero no dejan de plantear algunas dudas sobre el género que la gran bailarina frecuentaba. El fenómeno ocurría porque la tradición de la danza clásica, en México, a partir de le época colonial, indicaba situaciones escénicas menos "rígidas" o completas de las que la Pávlova, gran luminaria universal de la danza clásica, ofrecía al público del país. González Peña considera Giselle "indigno del genio de la Pávlova" el 17 de febrero de 1919 en su columna de El Universal, no obstante que el día anterior la Pávlova había bailado ante más de 16,000 personas que "retacaron" el Toreo de la Condesa. La bailarina había realizado una

brillante exhibición de su arte en una función de matinée. El costo de entrada en sombra fue de tres pesos, en luneta de cuatro y sol 75 centavos.

Las actuaciones de Anna Pávlova fueron, en México, sorprendentes incluso para ella. Las emociones del público y la extensa trayectoria de las "tablas", los espectáculos y la danza misma, en el país, apoyaron el lucimiento de esta singular mujer, enferma - literalmente- del arte de la danza.

Hay gente que se resiste a creer que la vida de una bailarina es lo contrario de la frivolidad. Pero, en realidad, la profesión de la bailarina es por completo incompatible con una forma de vida frívola. Si una bailarina, cayendo en la tentación, cesa de ejercer sobre ella misma el control más estricto, entonces hallará imposible seguir bailando. Debe sacrificarse en aras de su arte. ${ }^{3}$

Para la compañía de la Pávlova, México, a pesar de las primeras dificultades "logísticas" - como hoy se dice-, resultó un Edén: espectadores ávidos y querendones, buenos técnicos de iluminación, un nuevo bri1 lo de "ciudad cosmopolita" en la capital de la República y, por último,

2 "No sabemos en qué artes se aparecen el Duque y su hija. El casado despechado revela un enjuague. El conde se queda de una pieza. Giselle se vuelve loca, baila, baila y al fin se atraviesa el cuerpo con un tremendo espadón que encuentra a mano. Desmayos. Confusión. Carreras (iPronto, telonero, pronto! ¡Abajo el telón! ¡Abajo ¡)" "Citado en BHDM, 76.

${ }^{3}$ NPD, 10 (2a. p.). 
no malas instalaciones teatrales. Además debe agregarse el hecho de que durante los largos meses anteriores, la compañía de Pávlova había tenido que sufrir los reveses propios de una prolongada gira suramericana -venía de La Habana-, en la que los integrantes de su compañía habían incluso tenido que dormir en la cubierta de un barco, hacinados, revueltos con vestuario, escenografía y trastes o enseres escénicos. ${ }^{4}$ Los percances del viaje habían incluido la sensación de peligro que implica una temporada en la Ciudad de México, toda vez que el país se hallaba, en esa época, sacudido por los ventarrones de la Revolución.

Para que nada desagradable ocurriera, el presidente Venustiano Carranza ordenó que doscientos soldados permanecieran alertas, apostados en el techo de los vagones del ferrocarril que transportó a los artistas y a la Pávlova desde Veracruz a la Ciudad de México. ${ }^{5}$ Sin embargo, algún biógrafo de la bailarina registra una adversa circunstancia en la altitud de la ciudad capital ( 8000 pies, más de 2000 metros sobre el nivel del mar), de la misma manera que hoy en día bailarines y deportistas toman en cuenta y subrayan esta realidad geográfica, a veces para justificar o enaltecer su reducido o total lucimiento; no obstante, "la visita [de Pávlova] a México quedó marcada por una serie de triunfos", al grado de que se pensara en ofrecer matinées en la plaza de toros -con cupo para 30,000 almas-, lugar en donde bailó por primera vez "danzas mexicanas" ante la aclamación unánime de la concurrencia.

El propio González Peña acabó por elogiar las grandes dotes de la enorme bailarina y registró algunos acontecimientos importantes en el mundo del arte, como por ejemplo el encuentro artístico entre Casals y la Pávlova. Según Kerensky, ${ }^{7}$ la aparición del músico catalán en el escenario fue preparada sin el conocimiento de la bailarina, de manera que tuvo que acercarse a él bailando, sorprendida. Al final lo abrazó produciendo una total ovación de los espectadores. "El maestro acompañó con su violoncelo a la bailarina." que el público recibió fríamente a la Pávlova al iniciarse la temporada pero que después se le entregaba totalmente y demandaba más funciones, al grado de organizarse los dos estruendosos conciertos en la plaza de toros. ${ }^{9}$

$4 A P A, 150-152$.

* $A P A, 152$.

6 lbid.

7 AP, 49.

8 BHDM, 76.

9 AP, 49. 
Después de presentarse con éxito en el Teatro Arbeu, Anna Pávlova y su compañía hicieron su debut en el Teatro Principal el 20 de enero de 1919. El famoso "cuadro de ballet" estaba integrado de la siguiente manera: bailarinas absolutas: Anna Pávlova y Wlasta Maslova; maestro de baile: Ivan Clustine (del Teatro Imperial de Moscú); primera bailarina clásica: Hilda Butzova; primer bailarín: Alexandre Volinine (del Teatro Imperial de Moscú); director de la orquesta: Alexandre Smallens (de la Boston Opera); bailarinas: señoritas Linowska, Porter, Domislaswky, Shelton, Grabinska, Sakova, Stuart, Page, Saxova, Pajeska, Verina, Brunova, Sheffield, Zalewski, Veneloff, Harbin y Courteney; bailarines: señores Zalemnsky, Vajinski, Horelicks, Micholoff, Vorenszoff, Barte, Versseloff, Woronzoff y Oliveroff, además de otros cincuenta bailarines y bailarinas; la orquesta se componía de cuarenta ejecutantes. ${ }^{10}$

Los sucesivos programas que la compañía de la Pávlova cubrió en el Teatro Principal incluyeron, en la primera aparición, Orfeo y Copos de nieve, así como siete divertissements ("diversiones"). Al día siguiente fueron interpretados los siguientes "bailables": La flauta mágica, Preludios de Liszt y la ovacionada Muerte del cisne. Los días subsecuentes Pávlova y su compañía presentaron El despertar de Flora, Las siete hijas del rey duende, Raymunda, Amarillas, Bailes egipcios, El último canto, Invitación a la danza, Chopinianas, Thais, La bella durmiente y otros catorce divertissements.

La impresión que dejaron las "evoluciones" de la Pávlova en el escenario sirve para que algunos cronistas saquen a la luz pública, sin tamices y con evidencias lingüísticas, sus conceptos sobre el arte y la cultura.

Su nombre, repetido en clamores de gloria por la Fama, llegaba frecuentemente hasta nosotros, y la admirábamos desde lejos, como flor de refinada civilización que trascendía sus perfumes de Belleza en los centros cerebrales [sic] del Mundo, 'Venecias, Romas, vienas, Parises...'; y pensábamos que nunca vendría a esta vasta aldea de edificios monumentales y de costumbres pueblerinas que es México, porque sabíamos con Stevenson, que el Arte, como suprema floración de la vida [sic], brota expontáneamente [sic] en las sociedades que tienen un superavit de bienestar [sic], pero es la monstruosa flor de engaño que vio el autor de La llaga en los mármoles de nuestro petulante teatro Nacional en un país donde la mayoria de los habitantes viste de andrajos... Y sin embargo, Anna Pávlova vino a deslumbrar nuestras pupilas con el sortilegio de luz de los ballets que

10 HTPM, 383-384, 
tienen el mágico encanto de las figuras siempre vírgenes [sic] de un kaleidoscopio. 11

Ante el arte de la bailarina rusa, el cronista justifica la desventaja de las palabras para expresar las realizaciones de la danza. Pávlova es "divinamente única". Y delata González de Mendoza su empalagoso estilo confesando que "brotan los adjetivos como un surtidor de chispas" ante una "imposible onomatopeya visual", ante "esas escenas cuajadas de Gracia". Con respecto a los tipos de danza a los que el cronista se halla acostumbrado -podemos imaginar de qué danzas se trata-, confiesa por escrito:

Cierto es que nuestro vehemente temperamento latino que gusta de ver lumbres de pasión en los artistas, podría encontrar un tanto frías las danzas de la eximia étoille, acaso un poco angulosos, faltos de cálida morbidez, sus escorzos, pero este defecto, o esta cualidad, como gustéis nombrarle, queda compensado con la irreprochable perfección de una técnica tan precisa, de tanta simultaneidad con la música [sic], que se dijera que el sonido brota de un inmenso clave cuyas teclas rozara la danzarina con la breve punta de sus pies, a cada movimiento. ${ }^{12}$

Y a falta del lenguaje técnico, literario o periodístico adecuado, el cronista se remite a una combinación del Apocalipsis y sus imágenes infantiles afirmando rotundamente que Pávlova "es, en verdad, la última hada...".

Entre las crónicas del acontecimiento artístico que significó la visita de la Pávlova, también resulta curiosa una reseña en tomo a La fantasía mexicana, obra que la Pávlova of reció a México y sus mexicanos. Según parece, la obra tenía como tema principal El jarabe tapatío, contenía anécdota pueblerina y sus personajes no prescindían de los prototipos: la mujer "criollita" y humilde, el malo, la Patria; incluso habia evocaciones de las gestas históricas del país. Los elementos esenciales del bailado "de puntas" que de $E l$ jarabe tapatio hizo la Pávlova le fueron enseñados por Eva Pérez, una de las mejores bailarinas-tiples de la época y, como tal, ecléctica, técnica y formalmente; los diseños estuvieron a cargo de Adolfo Best Maugard. ${ }^{13}$ Poetas como Ramón López Velarde, Rafael

11 [J. M] González de Mendoza: "El arte de ensueño de Anna Pávlova", $A S$, Tomo I, Núm. 7, febrero de 1919.

12 lbid.

13 “Adolfo Best Maugard (1891-1964), cuya obra pictórica -retratos en su mayoría- no tuvo ni tiene mayor importancia, era por entonces un térico de peso 
López, José Juan Tablada y Enrique Fernández Ledesma dedicaron versos lucidores y sentidos a la Pávlova, pero una nota sencilla aparecida en El Universal Ilustrado el 28 de marzo de 1919, cuyo autor es Luis A. Rodríguez, revela en uno de sus fragmentos el hilo secreto que corría ya a lo largo de la idea de la danza en México:

Consuela ver que nuestros bailes nacionales, que hasta ahora se cultivaban en teatros de barriada, mañana, en la peregrinación artística de Ana Pávlova, serán exportados, y que públicos extranjeros al aplaudirlos conocerán que México, el país de maravillosa vitalidad, tiene su arte propio que está a una inmensa distancia del mal intencionado calambur de un popular actor y de las insulsas obrillas en que como tema reglamentario aparecen los más abominables pelafustanes de nuestros bajos fondos sociales.

La Pávlova aprovechó, entonces, no sólo los vientos de Revolución que azotaban por aquel entonces al país; tuvo la fina sensibilidad de atraer hacia su repertorio aspectos bastante lucidores de las danzas vernáculas y populares. Mediante el auxilio coreográfico y experimentado de Eva Pérez hizo a su numerosa compañía adentrarse en las prácticas de $E l$ jarabe, rasgo que fue aplaudido por el público y ensalsado por críticos y periodistas.

Ya para alejarse, y quizá como una gentil compensación a la extremosa galantería del público para con ella, Anna Pávlova ha bailado en una caprichosa estilización nuestro clásico baile vernáculo: el jarabe. Ante públicos extranjeros, tal ballet gustará seguramente, fuera si se quiere de la estética de su coreografía o de las bellezas melódicas de su música, por su matiz exótico que hace que siempre se acoja con aplauso a cuanto de estas tierras de América trasciende a otros continentes. Nuestro agradecimiento más efusivo a la insigne danzarina rusa por este simpático gesto suyo, de engarzar en el oro de altísimos quilates de su arte, una gema desprendida de nuestros ocultos y vírgenes tesoros populares. ${ }^{14}$

que coadyuvó a la afirmación del popularismo y el mexicanismo. Aplicando una lógica esteticista, habia catalogado la ornamentación popular reduciéndola a siete elementos básicos. Por un momento se creyó que gracias a su Método de Dibujo se produciría en las escuelas públicas del país el gran renacimiento del arte indígena; ilusión pueril que la más elemental sensatez no tardó en invalidar. Pero aquella revaloración no fue estéril; gracias a ella se comenzó a proteger y fomentar la producción de arte popular, evitando y postergando su desaparición. Sus formas, maneras y materiales constituyeron, a partir de entonces, una vereda transitada por los artistas cultos." Raquel Tibol en HGAM-VI, 260.

14 Roberto "El Diablo" en $R R, 30$ de marzo de 1919. 
Anna Pávlova acabó por fascinar a las multitudes. Privilegio del gran arte clásico, aquél que resulta completo, integrado, total. Por convertirse en "modelo", su lenguaje se hace universal, de tal manera que se incrusta en la tradición del arte del mundo occidental. En ese momento "culminante" de la Pávlova, resultaba cierto que

de las numerosas técnicas, es la de la llamada danza clásica - término que designa el estilo de danza que se fundamenta en la técnica tradicional del ballet - la que ha prevalecido en el mundo occidental. Parece coincidir por completo no sólo con la estructura anatómica del europeo sino también con sus aspiraciones intelectuales. ${ }^{15}$

Si existe una literatura "clásica", universalmente entendida y asimilada -como el Quijote, Las mil y una noches, la Biblia-, existe una danza "clásica" que va más allá de la técnica que la ampara —o más bien, que constituye el más alto grado de calidad gracias a la depuración y el dominio de esa técnica-; tal el caso de las obras que Pávlova seleccionaba e interpretaba. En sus ejecuciones, el público, aún no familiarizado con el lenguaje que tenía ante sus ojos, percibía el fenómeno artístico, lo sentía en la piel y en el organismo, lo aceptaba, entendía y aclamaba. La fama definitiva de Pávlova se hacía patente en cualquier tipo de espacio escénico y no por mero bombardeo de anteriores datos o información, sino por el atractivo que su figura sabía y podía ejercer directamente, al "presentarse" en el foro y al ejecutar sus acciones dancísticas. Los espectadores comprendían que se hallaban ante un momento "grandioso", irrepetible, único, verdadero. Y Pávlova sabía que no era un mero asunto de "promociones", modas o contingencias:

En países lejanos se ha dicho que hay algo "novedoso" en mi danza. Sin embargo, lo que yo he hecho consiste solamente en subordinar los elementos físicos de este arte a un concepto psicológico: sobre los aspectos fehacientes de la danza -o sea, de la danza per se- he intentado lanzar un velo espiritual, de poesía...16

Cuando en la danza clásica se habla de virtuosismo, madurez y recrea"ción, los términos implican una especie de "trance" por encima de otro requisito fundamental: el dominio riguroso e inobjetable de una técnica rigurosa, exigente y reconocida por la tradición. De esta manera, en ge-

16 APAN, 47. 


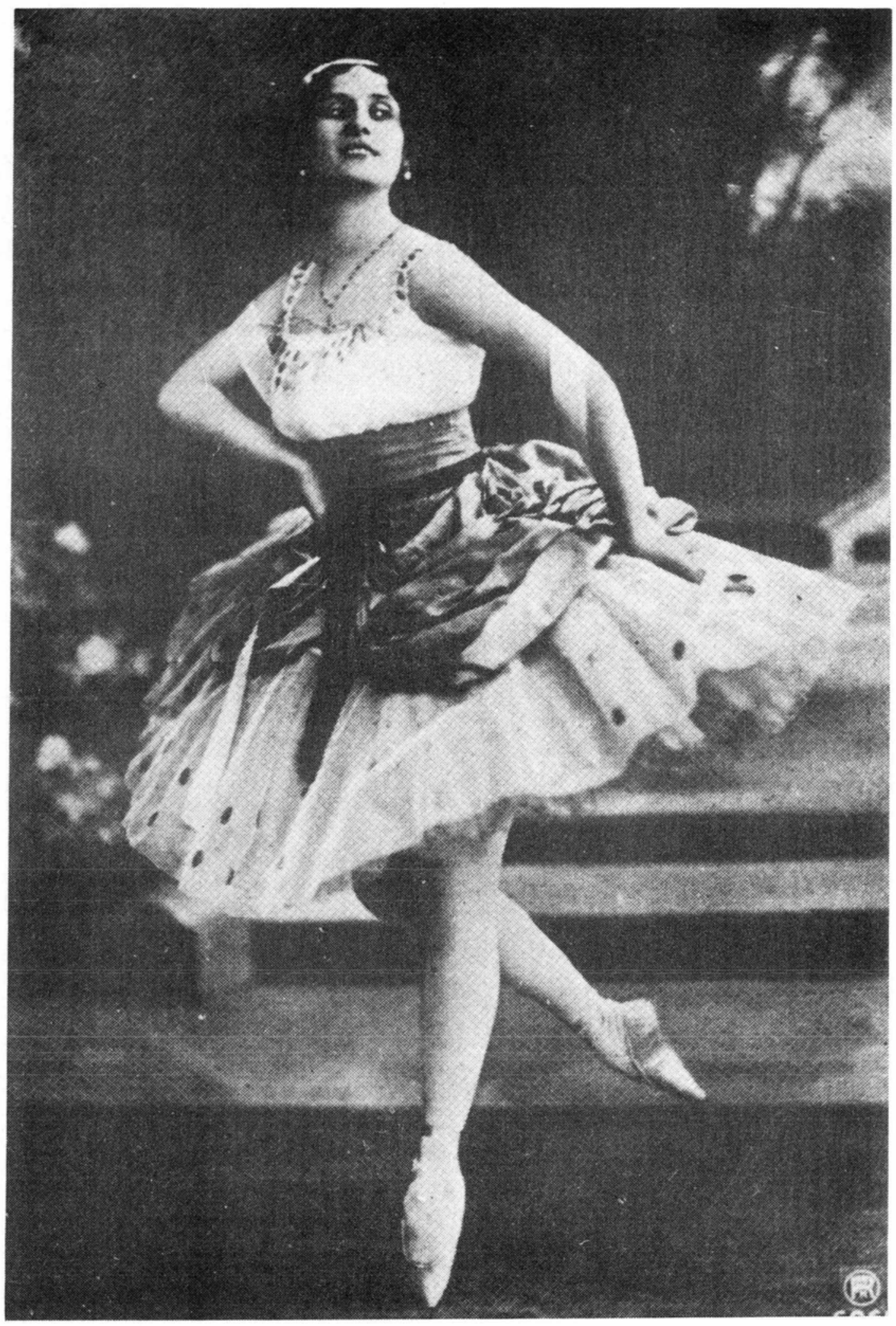

1. Anna Pávlova en Paquita. San Petersburgo, circa 1908. 
DOI: http://dx.doi.org/10.22201/iie.18703062e.1989.60.2379

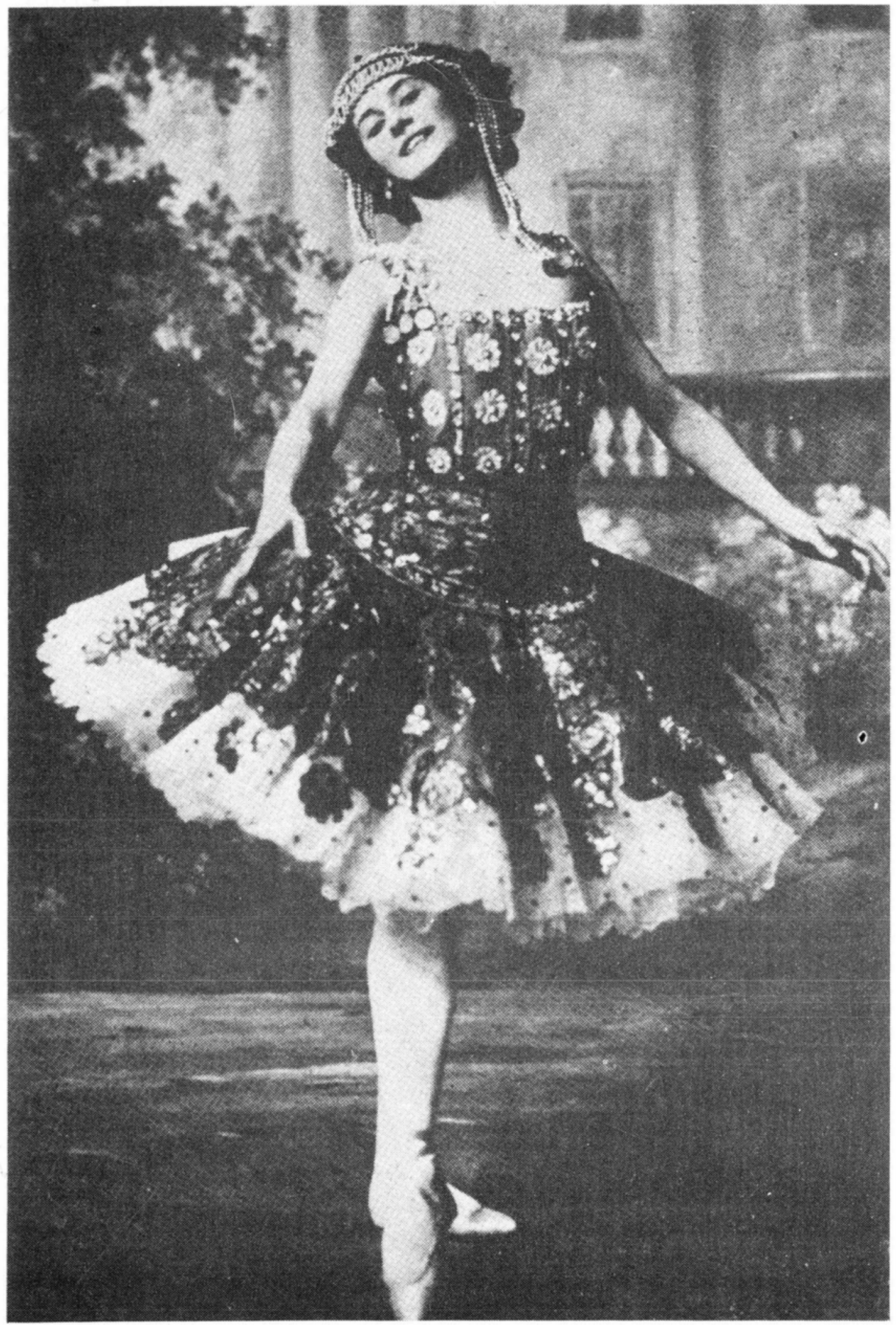

2. Anna Pávlova en Don Quixote, San Petersburgo, circa 1908. 
DOI: http://dx.doi.org/10.22201/iie.18703062e.1989.60.2379

3. Anna Pávlova y Volinine en El jarabe tapatio, México, 1919.

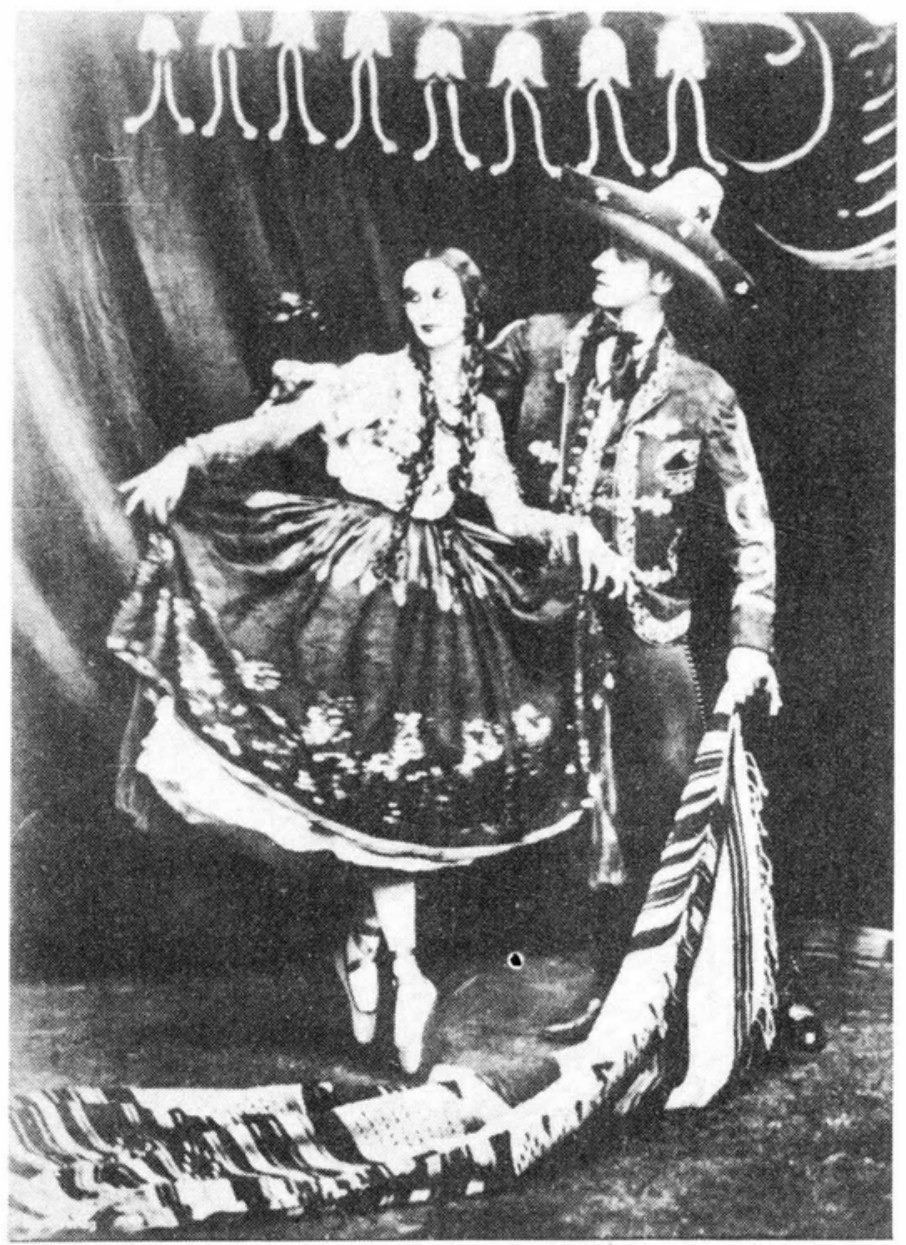

4. Anuncio en Excélsior de la temporada de Pávlova, 1919.

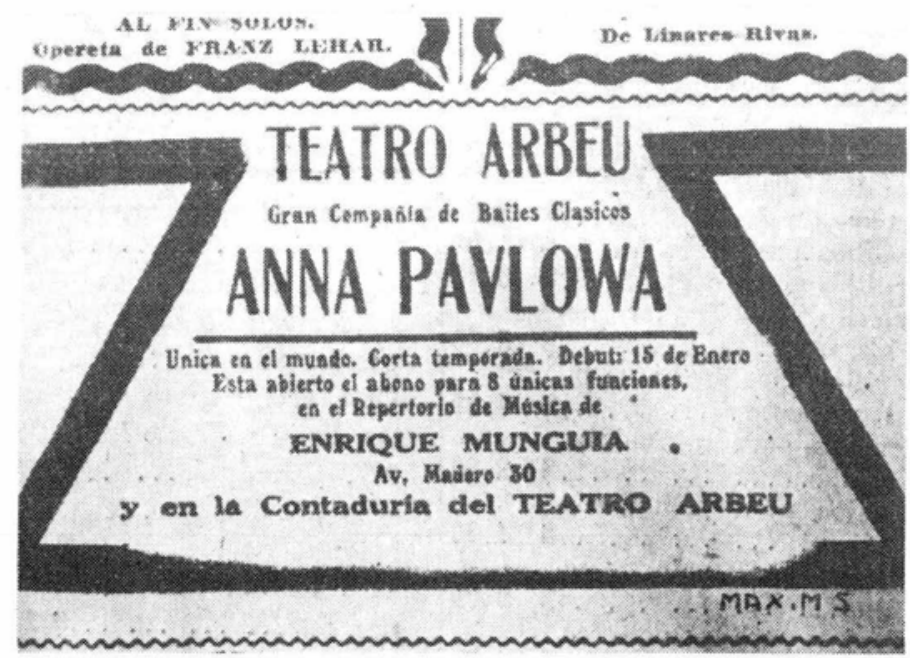


DOI: http://dx.doi.org/10.22201/iie.18703062e.1989.60.2379

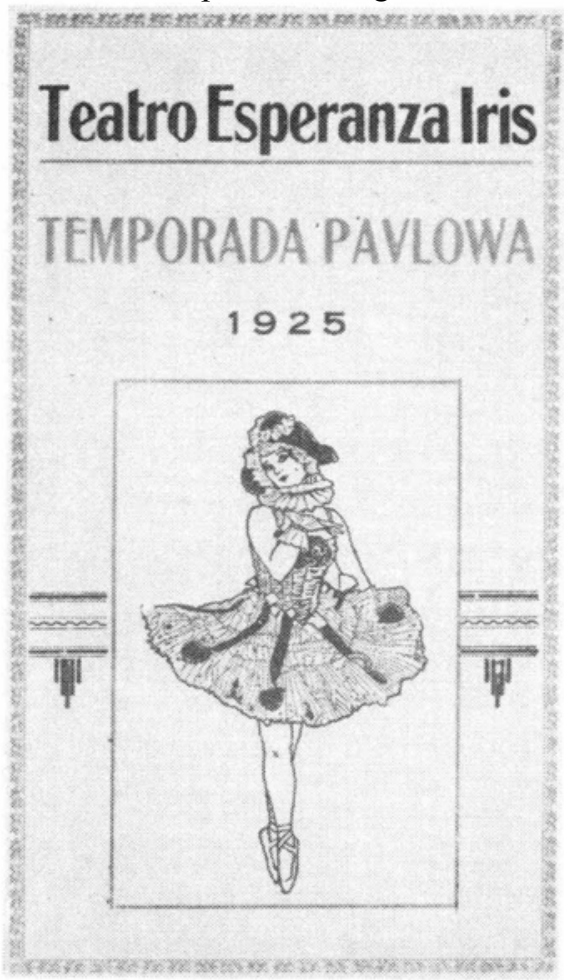

5. Portada del programa de mano de la temporada de despedida de Pávlova en México.

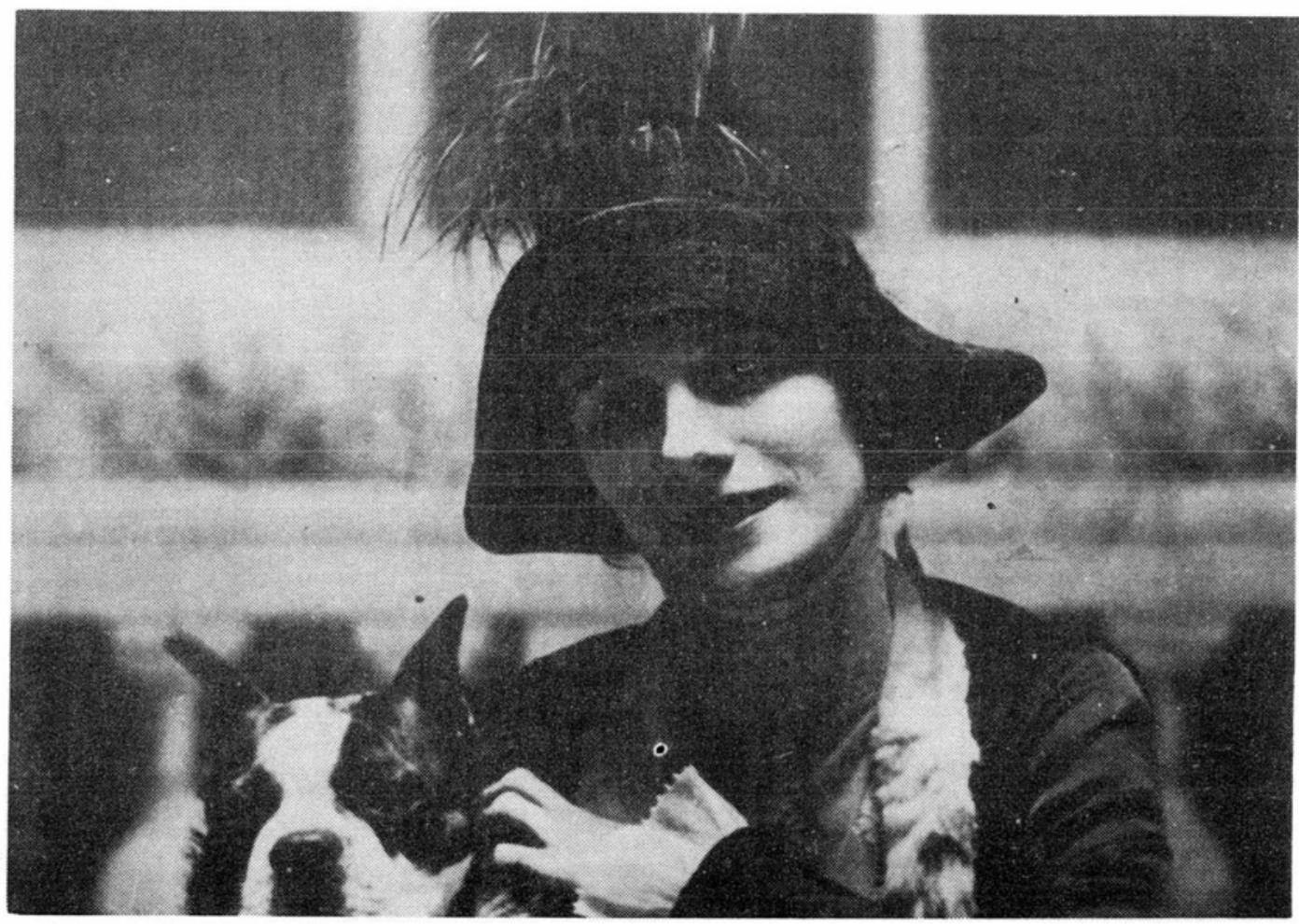

6. Pávlova en México, 1919. 
neral, las obras de la danza clásica, como lenguaje, ${ }^{17}$ van más allá de las historias que "narran" o cuentan: expresan una actitud $-\mathrm{y}$ por ello pueden ser un lenguaje-; el ejecutante está obligado, por así decirlo, a "detener la narración" y realizar la gran proeza, a apoderarse del "instante" o de la secuencia y no sólo hacer lo que el público sabe y le exige que debe hacer, sino alcanzar algo más: la perfecta armonía entre la expresión y la forma. Será grande en la medida en que no sólo cumpla con los requisitos que la obra "exige" sino que superando estas implícitas peticiones o normas, logre "arrebatar" las emociones, es decir, toque las fibras internas, orgánicas, humanas y hasta biológicas de sus espectadores.

Aunque el ritmo es la repetición o de un sonido o un efecto mediante intervalos regulados, la independencia con respecto al ritmo es esencial, y Pávlova jamás se satisfizo con las literalidades de la técnica; sus invenciones -el quiebre en puntas, la prolongada pausa en puntas, la piroutte agitada - fueron, ciertamente, una prolongación temperamental de las convenciones aceptadas..$^{18}$

Las cualidades de la Pávlova fueron captadas de inmediato por los escritores mexicanos. En la sensibilidad inhabitual de Ramón López Velarde, Anna Pávlova se convierte no sólo en un cuerpo femenino sino en una geografía de sensaciones, sentimientos, procesos y mecanismos. La perfección de sus ejecuciones impresionan al poeta mexicano y lo hacen reconocer, mediante una mezcla de sugestivas imágenes, la fuerza de atracción y de suscitación que ejerce el gran arte, cuando éste, según las exigencias del género, cuenta con un artista virtuoso que combina el dominio de los procedimientos y la re-creación de las formas.

\section{ANNA PÁVLOVA}

Piernas
eternas
que decís
de Luisa La Vallière
y de Thaís...

$17 C A D, 89-90$.

$18 A P A V, 50$. 
Piernas de rana,

de ondina

$y$ de aldeana;

en su vocabulario

se fascina

la caravana.

Piernas

en las cuales

danza la Teología

funerales

y epifanía.

Piernas:

alborozos y lutos

y parodias de Atributos.

\section{Piernas}

en que exordia

la Misericordia

en la derecha,

y se inicia

en la otra la Justicia.

\section{Piernas}

que llevan del muslo al talón

los recados del corazón.

\section{Piernas}

del reloj humano, certeras como manecillas, dudosas como lo arcano, sobresaltadas con la coquetería de las hadas.

\section{Piernas}

para que circuyas

el espíritu, que se desarma

entre tus aleluyas; 


\begin{abstract}
si la violeta de Parma
tuviese piernas,

serian las tuyas.

Mistica integral,

melómano alfiler sin fe de erratas, que yendo de puntillas por el globo las libélulas atas y desatas.
\end{abstract}

iTe fuiste con mi rapto y con mi arrobo, agitando las ánimas eternas en los modismos de tus piernas! ${ }^{19}$

Pero la presencia de Pávlova en México representa algo más, y lo percibimos no sólo en la impresión que deja en López Velarde, poeta que, como pocos, conocía a la perfección el concepto de los bailarines en torno a que "el tiempo es nuestra propia vida". ${ }^{20}$ Pávlova significó también, para muchos, los más sensibles, la "entrada en materia" de la "erudición dancística" y el virtuosismo, la pasión y la "entrega" (como en los toros) a la danza. Sólo Pávlova y unas cuantas figuras, dominadoras de este arte - y a la manera como lo hicieron-, pudieron hacer al público cimbrarse, percibir la mezcla de júbilo y agonía que implica la perfección intransigente de la danza. En el pasado, ninguna bailarina había representado - literalmente y a la vista de todos- ese summum de intensidades, conocimientos, técnicas y recursos. Tal vez en alguna ocasión María de Jesús Moctezuma ${ }^{21}$ o la Cordero hayan hecho vislumbrar o percibir el anuncio o el aura de tales sensaciones de unión ejecutantepúblico. Lo lograrían tan sólo, en el lapso de treinta años a partir de la visita de Loie Fuller en 1897, 20 Pávlova, Antonia Mercé "La Argentina", Tórtola Valencia --posiblemente, aunque sus rutinas fueran más del lado de la gracia y la diversión- y alguna que otra bailarina del ambiente farandulesco: verdaderos fenómenos que dejan huella en las mentes de sus espectadores, en el periodismo, la literatura y la poesía. Artistas cuyas obras y representaciones literalmente "hacen historia".

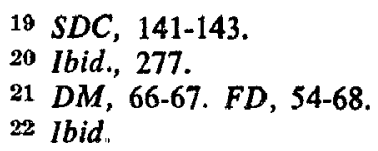




\section{Vuelve la Pávlova}

En abril de 1925 Anna Pávlova regresó a la Ciudad de México. La función del 23 de abril consignaba el estreno nacional del sensacional ballet Don Quijote (México es el primer país de habla española que podrá admirar esta maravillosa creación de la compañía Pávlova). Ballet en dos actos, arreglo de Laurent Novikoff. Música de Minkus. El decorado fue diseñado por C. Korovine y ejecutado por él mismo y C. Allegri. El vestuario fue hecho por la casa Weldy de París. ${ }^{23}$

Bailaban: Salewski, Pávlova, Novikoff, Pianovska, Volinine, Fedorova, Nikita, Stuart, Domoslawski, Markowski y Butsova. En el mismo programa se ofecían siete Divertissement que terminaban con las Danzas sirias que interpretaba Anna Pávlova con música de Saint-Saëns, acompañada por Novikoff, Domoslawski, Nichols y Winter.

A Carlos González Peña, sin embargo, no le gustó tanto hallarse de frente con un Don Quijote bailado. Literato al fin, se queja de los desaguisados perpetrado con base en el texto de Cervantes, con el famoso Caballero de la Triste Figura, no sólo en esta obra balletística de Novikoff sino -incluso- en las numerosas puestas en escena europeas durante varios siglos. Todos los lectores de González Peña saben en los años veintes que el crítico es intransigente con el manoseo de formas artísticas hechas y derechas y deducen que al escritor y estudioso de la literatura hispánica pueden molestarle malas o deficientes interpretaciones del personaje. Sin embargo, González Peña no resulta muy descriptivo de la obra dancística de Novikoff y se lanza en el texto a emitir una larga y bien documentada queja sobre la sustitución reiterada de la obra de Cervantes en la ópera y el teatro de países distintos de España. Mediante su estilo incisivo, confiesa que, al re-encontrar al Quijote en el ballet,

Nunca pensé encontrarle entre bailarinas, ensayando un paso a dos. Ni se me acurrió que la zafia Aldonza Lorenzo, con "maillot" y enaguiillas, lo engolosinara con un "pizzicatto". Pero -iqué quieren ustedes! - me tro. pecé con él en el teatro de la calle de Donceles. El señor Laurent Novikoff lo "desgraciaba" nuevamente, presentándonoslo, primero, no en el humilde cuarto polvoso donde se amontonaban Amadises y Palmerines y al cual penetraron el cura, el ama y la sobrina; sino en una especie de interior de catedral, donde había hasta libro de coro. Llevábale después a Barcelona, a un mercado - ia un mercado del siglo XVI! - entre toreros

23 Programa de mano, lujo, 1925. 
y manolas de los tiempos de Goya. Hacíale vencer, en fin, no por el $\mathrm{Ca}$ ballero de la Blanca Luna, sino por otro, de la particular invención del señor Novikoff: el del Escudo de Plata. iY todo concluía entre saltos y piruetas, llevando el desdichado Don Quijote, a título de condecoración, una banda o chal coruscante que Dulcinea le había cruzado sobre el pecho! .. . Dicen que esta farsa tuvo gran éxito en Londres y en Nueva York. Y yo no lo dudo... Oh, pero cómo te han puesto, mi pobre Caballero! Si Miguel de Cervantes resucitara y te viese, no te reconocería. . ${ }^{24}$

Resulta extraño, sin embargo, que González Peña no se sintiera satisfecho con una obra ya para su época tradicional del repertorio clásico y, sobre todo, que no aludiera a la coreografía de Marius Petipa estrenada por el Ballet Imperial Ruso en 1869. La versión de Laurent Novikoff que bailaba la compañía de la Pávlova se componía de un prólogo y dos actos, a diferencia de la original que entretejía la vida del manchego en cuatro actos y ocho escenas. Esta omisión -tal vez por desconocimiento- de González Peña indica el reducido arraigo que en México, hasta esas fechas, existía en torno a la danza clásica "hecha y derecha", o sea, el ballet europeo de siglos anteriores.

Habían transcurrido seis años desde la última vez que Pávlova había actuado en México. Se trataba de otra de sus apoteóticas presentaciones en el continente americano pero, desgraciadamente -apuntaba, en inglés, el programa-, se trataba de la última gira americana de la gran bailarina:

Adiós, Pávlova. América no la verá otra vez tras esta gira de despedida. En el futuro se presentará solamente en cortas temporadas anuales en Londres y París. Sólo trabajo y nada de diversión han llenado su carrera en el pasado. En el futuro habrá vacaciones principalmente y sólo viajes de placer. Su bella residencia en Golders Green, Londres, que la ha recibido sólo durante cortas visitas veraniegas, constituirá su verdadera casa y tendrá tiempo y libertad para ir y venir, para pasear en Italia, España, Rusia, Francia o cualquier otro sitio de acuerdo a sus deseos... Ha comenzado a divertirse en el momento adecuado (to play in the midst of her prime). Ninguna artista ha trabajado tanto ni de manera más sincera que Påvlova, y el trabajo la ha mantenido joven. No permanecerá inactiva en el futuro: sólo permanecerá libre. Se ha hecho acreedora a todos los honores posibles en muchos países y su cuarto de trofeos en su residencia contiene maravillas de estos tesoros. Como Alejandro el Grande, Pávlova no tiene nuevos mundos que conquistar $y_{3} \sin$ embargo, no se entristece. $^{25}$

$24 A M, 50-51$.

25 Programa de mano, lujo, 1925. 
Fino y, a la vez, perceptivo y conocedor, Carlos González Peña hizo la crónica -más literaria que dancística- de la visita de la gran Pávlova. Captaba, en toda su dimensión, el significado de la presencia de la bailarina:

Esta artista que, en nuestra época, como en el pasado Mlle. Sellé o la Camargo, María Taglioni o Fanny Elssler, es la encarnación de la danza, la danza misma hecha mujer, se retira de los escenarios. Se dispone a morir; qué dulce muerte será para ella la vida, desde el momento en que se recluya en sus mágicos palacios, entre las brumas británicas o las nieves alpinas. Pero antes, antes de penetrar en la vasta sede de la quietud y del silencio, ha querido hacer a México, a título de despedida, el don regio de su genio y de su arte incomparables; y loada sea por tan buena determinación.

Intransigente en lo que respecta a la calidad de la danza, González Peña aprovecha su texto en torno del arte de Anna Pávlova para recordar a sus lectores que no todo lo que ocurre en el escenario, aunque así se le llame, es, cabalmente, danza. Y sobre el tema desarrolla una vasta idea de que hay signos y elementos, dentro de un espectáculo de danza, para poder discernir sobre la autenticidad del arte que se le ofrece al público. Afirma:

Tiempo ha, Camilo Saint-Saëns decia: 'Después de las óperas en que no se debe cantar, nos llegan 'ballets' en que está prohibido bailar'. Tan irónico comento, sin duda, se lo sugirieron al creador de Sansón y Dalila las exageraciones -inevitables fatalmente- a que dio margen la renovación modernísima del arte de la danza. . . Y yo he recordado esas palabras asistiendo a las espléndidas veladas del 'Iris'. Trájolas a mi mente, por contraste, el advertir que siendo el de la Pávlova un espectáculo de 'ba llet' moderno, lo que en él se mira, ante todo, es bailar y siempre bailar. La actitud, la 'pose', no priva alli sobre el movimiento; hermana con el, se origina de él... Y es que Ana Pávlova ha realizado el principio admirable de innovar sin romper los moldes clásicos. El drama mímico musical moderno se asocia en ella a la vieja danza. Su arte, como la divinidad antigua, tiene dos caras: una vuelta al pasado; otra sonriendo al porvenir. 26

Y como para esas fechas ya se hacian evidentes los signos del vasto movimiento que implicaba la danza moderna - nuevo género surgido como reacción a las finuras y heladeces del ballet clásico-, González

$26 A M, 110 \cdots 111$ 
Peña aprovecha el inigualable arte de la Pávlova para lanzar reproches a las nuevas intérpretes que se atrevieran, sin ton ni son, a llamar danza a cualquier cosa:

Vulgar creencia es la de que basta desnudarse las piernas, vestir una túnica, dar tres volteretas y ensayar, con ramos y remos, media docena de gestos estrafalarios, para constituirse en la personificación misma del 'ballet' moderno. Así hemos conocido alguna vez a bailarines que no bailan; a falsas 'Isadoras' que nos dan el camelo de revelarnos titos esotéricos.

Y para subrayar el talento y las dotes, la experiencia y la belleza y pulcritud interpretativas de, en ese momento, la más grande bailarina del mundo, González Peña sitúa la actitud estética de Pávlova, especificando sus descubrimientos en las plenas, últimas actuaciones de la artista:

Ella, ante todo, baila. Y si su baile es un prodigio, algo que toca los linderos de lo sobrenatural, la esencia misma de lo perfecto, por la pureza, por la sabiduría técnica, por la agilidad portentosa; su arte mímico, su potente fuerza expansiva de actriz muda, irradia también gloriosamente... Son múltiples, y de estatuaria gallardía, sus actitudes. Se encadenan y suceden hasta lo infinito, en forma de que no hay humanos ojos capaces de retenerlas. No bien una nos subyuga, viene otra a suplirla. El encanto total lo sentimos al fin: cuando gestos y movimientos, armónicamente dis" tribuidos, han creado en nuestra retentiva, en nuestros nervios, la obra maestra sin par. ${ }^{27}$

$Y$ en la adornada pero asimismo verosimil descripción, con lenguaje impecable, González Peña explica cómo baila la Pávlova:

Cuando sobre las puntas de los pies gira y piruetea, nos da la impresión de que se levanta, de que asciende, emancipada de la pesantez. Su cuerpo se alarga, se afina milagrosamente, y las manos en alto, las manos en que los dedos afilados, como en las figuras de Botticelli, prolongan, plenos de misterio, la actitud del vuelo, son como el extremo impreciso de esbeltos pistilos de una soñada flor. ${ }^{28}$

Después de su presentación en México, la Pávlova realizó giras en el continente europeo y Egipto, Java e India. El 13 de diciembre de 1930 baila su Giselle por última vez en Londres (con Vladimiroff como partenaire) y muere el 23 de enero de 1931 en La Haya, Holanda. Sus cenizas se hallan en Golders Green, Londres.

27 Ibid., 111.112.

28 Jbid., 111. 


\section{SIGLAS}

AM Carlos González Peña: El alma y la máscara, Editorial Stylo, México, 1948. $283 \mathrm{pp}$.

AP Oleg Kerensky: Anna Pavlova, E. P. Dutton and Co., New York, 1973.

APA V. Svetloff: Anna Pavlova, Dover Publications, New York, 1974. 196 pp.

APAV Marianne Moore: "Anna Pavlova", Dance Index, Vol. III, Núm. III, Marzo de 1944.

AS Album Salón.

BHDM Luis Bruno Ruiz: Breve historia de la danza en México, Ediciones Libro-Mex. 1956. 144 pp.

CAD Alberto Dallal: Cómo acercarse a la danza, Secretaría de Educación Pública/Gobierno del Estado de Querétaro/Plaza \& Valdés, $1988.156 \mathrm{pp}$.

DM Alberto Dallal: La danza en México, Estudios y Fuentes del Arte en México/LVIII, Instituto de Investigaciones Estéticas, Universidad Nacional Autónoma de México, 1986. 310 pp. + 64 ilustr.

DTA Selma Jeanne Cohen (ed.): Dance as a theatre art, Dodd, Mead and Co., New York, 1975. 224 pp.

FD Alberto Dallal: Fémina-Danza, Cuadernos de Historia del Arte/ 21, Instituto de Investigaciones Estéticas, Universidad Nacional Autónoma de México, 1985. 200 pp. + ilustr.

HGAM Varios autores: Historia general del arte mexicano, Editorial Hermes, 1975. Ocho tomos.

HTPM Manuel Mañón: Historia del Teatro Principal de México, Prólogo de Juan Sánchez Azcona, Editorial Cultura, México, 1932. $470 \mathrm{pp}$.

NPD Paul Magriel (ed.): Nijinsky, Pavlova, Duncan, Da Capo Press, New York, 1977. $81+78+85$ pp.

$R R \quad$ Revista de Revistas.

SDC Ramón López Velarde: Poesías completas, El minutero, Don de febrero, Prólogo de Margarita Villaseñor, Promexa Editores, 1979. $342 \mathrm{pp}$. 